\title{
Towards a European Term for Complementary and Alternative Medicine (CAM): Complementary European Medicine (CEM)
}

\author{
Bernhard Uehleke Reinhard Saller \\ Institute of Complementary Medicine, University Hospital Zürich, Switzerland
}

There are mainly two terms used for our area of work (as a researcher or as a specialized physician): 'alternative medicine' and 'complementary medicine'. Differences in understanding of these terms are marginal, and even in scientific literature these terms are often used as synonyms. The combined phrase 'CAM', however, is quite an academic term and is not used by laypersons [1], who stick to the shorter terms such as 'alternative medicine' or 'complementary medicine'. In Europe many other terms had been in use before 1970s, e.g. 'biological medicine', 'holistic medicine' or 'experience-based medicine', and also 'natural medicine' (in an extended meaning) was used long before US researchers became aware of that field in the 1990s. However, terms are culture-related [2] and change over time and are differently applied within subgroups.

Any definition of a generic term for our area of expertise should be clear as to which disciplines and methods are included and which not because they are regarded to belong to the fields of e.g. conventional medicine, psychology or psychotherapeutics and also with regard to boundaries against lifestyle aspects or religious activities. If a term is fuzzy with regard to these boundaries, an additional compilation of methods and treatment concepts included must be provided. However, with regard to the generic term CAM, such compilations are often inconsistent or even arbitrary. There are significant country-specific differences as to which therapies would be considered as part of CAM.

When comparing various definitions of CAM, it becomes apparent that US definitions are rather heterogeneous and arbitrary with regard to the procedures and therapeutic concepts included. This might be due to the sort sequence by mode of action which is accompanied by overlappings and double entries. Moreover, multiple modes of action and ho- listic' approaches as claimed by a considerable number of alternative therapies are neglected.

Furthermore, CAM and 'integrative medicine' are increasingly intermingled, resulting in acronyms such as 'CAIM' (complementary, alternative and integrative medicine) or 'CIM' (complementary integrative medicine'). The term 'CIM' was recently brought up by Eisenberg [3], clearly reflecting the US perspective of the author that ignores earlier developments in Europe and also in North America in the 19th and 20th century and focuses only on the enormous spread of CAM therapies in the 1990s. However, the philosophy of 'integrative medicine' is characterized predominantly by a broad and personalized patient care in a certain setting of provision, and not by a set of certain therapies and treatments added to those of conventional medicine. This concept does not find common consent, and especially non-medical practitioners opposed this concept as they do not see the necessity to have their treatment supervised by a medical doctor. In many European countries such non-medical practitioners are an essential part of the healthcare system the treatments of whom are requested and called on by a considerable number of patients.

In most European countries some disciplines listed in the American definitions of CAM would not be regarded to belong to medicine at all. For example, American definitions of CAM include praying with a high prevalence (one might speculate that this is due to the strong influence of certain pressure groups in the USA benefiting from this inclusion). Thus it seems obvious that there are relevant differences between the American and the European definition of CAM justifying a differentiation between both.

Even if we should keep in mind that meanwhile, at least in countries such as the UK, Switzerland and Germany, the

\section{KARGER \\ Fax +497614520714 \\ Information@Karger.de}

www.karger.com (c) 2011 S. Karger GmbH, Freiburg

1661-4119/11/0182-0066 \$38.00/0

Accessible online at:

www.karger.com/fok
Dr. med.Bernhard Uehleke

Institute of Complementary Medicine

University Hospital Zürich

Rämistraße 100, 8091 Zürich, Switzerland

bernhard.uehleke@usz.ch 
term 'complementary medicine' is widely spread and known in the public as well as in legislation [4], one easy way out of this confusion of ideas mentioned above could be to just drop the A in CAM and replace it by E for European. Then 'CEM' would be the acronym for Complementary European Medicine. North Americans might continue with CAM, but eventually with a new meaning: 'Complementary American Medicine'.

A definition for CEM could easily be achieved by just adding the sets of medicinal disciplines which are in use in European complementary medicine:

1. Traditional European Medicine (TEM) [5] and traditional European natural healing methods (TEN), i.e. the classical natural medicinal methods of water- and thermotherapy, diet and fasting, body exercise and massages, herbal medicines and 'Ordnungstherapie' (including mind-body therapies) [6];

2. specific European medicinal systems such as homeopathy, anthroposophy and neural therapy;

3. adapted systems introduced from other traditional medicines such as TCM or Ayurveda or single methods such as yoga or Tibetian herbal drugs being originally part of the above mentioned traditional medicinal systems;

4. other unconventional medicinal methods used in Europe. An increased consideration of Traditional European Medicine as mentioned above may contribute to a more balanced definition of traditional medicine by the WHO. We are looking forward ...

\section{References}

1 Caspi O, Sechrest L, Pitluk HC, Marshall CL, Bell IR, Nichter M: On the definition of complementary, alternative, and integrative medicine: societal mega-stereotypes vs. the patients' perspectives. Altern Ther Health Med 2003; 9:58-62.

2 Lewith G: The cultural context of CAM. J Altern Complement Med 2008;14: 1179-1180.

3 Eisenberg DM: Trends in integrative medicine: a U.S. perspective. Eur J Integr Med 2010;2:160

4 Saller R: Komplementärmedizin in der Verfassung: die Schweizter Bevölkerung hat entschieden. Forsch Komplementmed. 2009;16:216.

5 Uehleke B: Naturheilverfahren und «Traditionelle Europäische Medizin» (TEM): Ergebnisse einer Experten-Umfrage (Delphi-Methode). Schweiz Zschr Ganzheitsmedizin) 2007;19:199-203.

6 Melzer J, Melchart D, Saller R: Entwicklung der «Ordnungstherapie» durch Bircher-Benner in der Naturheilkunde im 20. Jahrhundert. Forsch Komplementarmed Klass Naturheilkd. 2004;11:293-303. 
Forschende.

Komplementärmedizin

Wissenschaft • Praxis • Perspektiven

\section{Erratum}

Forsch Komplementmed 2012;19:111

In the editorial

Uehleke B, Saller R: Towards a European Term for Complementary and Alternative Medicine (CAM):

Complementary European Medicine (CEM)

published in Forschende KomplementÄRMEDIZIN 2011, volume 18, issue 2, pp 66-67 the 'Acknowledgement' statement (see below) was missing.

\section{Acknowledgement}

First author Bernhard Uehleke was partially paid by a grant from the European Community's Seventh Framework Programme (FP7/2007-2013) under grant agreement No. 241951. 